\title{
Characterisation of Beaver Habitat Parameters That Promote the Use of Culverts as Dam Construction Sites: Can We Limit the Damage to Forest Roads?
}

\author{
Geneviève Tremblay ${ }^{1,2}$, Osvaldo Valeria ${ }^{1, *}$ and Louis Imbeau ${ }^{1}$ \\ 1 Centre D'étude De La Forêt, Institut De Recherche sur Les Forêts (IRF), Université du Québec en \\ Abitibi-Témiscamingue (UQAT), 445 Boulevard De L'université, Rouyn-Noranda, QC J9X 5E4, Canada; \\ genevieve.tremblay@lacsimon.ca (G.T.); louis.imbeau@uqat.ca (L.I.) \\ 2 Conseil De La Nation Anishnabe Du Lac Simon, Département des Ressources Naturelles 1026, Boul. Cicip, \\ Lac Simon, QC J0Y 3M0, Canada \\ * Correspondence: osvaldo.valeria@uqat.ca; Tel.: +1-819-762-0971 (ext. 2384); Fax: +1-819-797-4727
}

Received: 5 October 2017; Accepted: 5 December 2017; Published: 9 December 2017

\begin{abstract}
The use of forest roads as foundations for dam construction by beavers is a recurrent problem in the management of forest road networks. In order to limit the damage to forest roads, our goal was to calculate the probability of beaver dam installation on culverts, according to surrounding habitat parameters, which could allow for improvement in the spatial design of new roads that minimise conflicts with beavers. Comparisons of culverts with $(n=77)$ and without $(n=51)$ dams in northwestern Quebec showed that catchment surface, cumulate length of all local streams within a 2-km radius, and road embankment height had a negative effect on the probability of dam construction on culverts, while flow level and culvert diameter ratio had a positive effect. Nevertheless, predicted probabilities of dam construction on culverts generally exceeded $50 \%$, even on sites that were less favourable to beavers. We suggest that it would be more reasonable to take their probable subsequent presence into account at the earliest steps of road conception. Installing mitigation measures such as pre-dams during road construction would probably reduce the occurrence of conflicts with beavers and thus reduce the maintenance costs of forest roads.
\end{abstract}

Keywords: road; beavers; dam; habitat parameters; boreal forest

\section{Introduction}

In Canada, transportation of wood between forests and mills is mainly overland, which requires the construction and maintenance of an important road network. To prevent road damage, several forest industries and associations throughout North America need to decrease the densities of beavers, which represent a significant issue wherever they are naturally established [1-4]. Indeed, beavers frequently use roads as the foundations for dam construction, which is a recurrent problem in the management of forest road networks. Dams are usually located on the upstream side of roads, usually a few metres away or even within culverts, i.e., structures that are supposed to allow the free movement of water between the two sides of roads. Road embankments also facilitate dam construction, because they prevent water flow and may seem attractive to beavers. Embankments have the effect of raising the water table, while lowering the water table downslope, and concentrating the flow at the culvert level [5]. When the culvert is blocked and water accumulates upstream, significant infiltration will occur, leading to destabilisation of roads, frequent flooding and even complete road erosion at the time of severe flooding [6]. This damage obviously represents significant road network maintenance costs, often at the expense of forest companies, in several Canadian provinces. 
Following a major population decline that was related to trapping from the beginning of European settlement of northeastern regions of North America, several beaver populations have apparently increased at a time when the forest road network in the boreal zone is still rapidly growing. For example, according to the report of [7] and data obtained from the Ministry of Natural Resources and Wildlife of Quebec [8], the network length of permanent forest roads throughout Quebec has tripled over the last 30 years, while timber harvest increased only about $60 \%$. Indeed, the road construction rate increased from $150 \mathrm{~km} /$ year in the late $1970 \mathrm{~s}$ to $300 \mathrm{~km} /$ year in the late 1990s. As a result, an estimated 10,000 culverts are installed on new roads or repaired within the existing road network every year throughout the province of Quebec [7]. Within this context, potential conflicts between beavers and users of forest roads are likely to increase in the coming years.

In order to limit the damage that is caused to roads by beavers, the effectiveness of different control systems has been the subject of several recent studies [2,4,9]. Control measures have included systems that are aimed at preventing culvert blockage by beavers or for maintaining water level control. These systems require rigorous maintenance and other measures, such as trapping. These approaches are effective occasionally and, therefore, short-lasting [6]. Thus, long-term management approaches that limit the risk of damage to forest roads by beavers are greatly needed.

One of the first steps toward longer-term management to limit risks to road infrastructure is to increase our understanding and approaches to modelling beaver habitat. Generally, geomorphological variables are more useful than variables reflecting food availability in explaining habitat use by beavers $[10,11]$. We consider the following variables to be appropriate for dam-site selection: stream gradient [12,13], dam upstream catchment area [13,14], Strahler order [15], channel geomorphic unit (stream width, depth or cross-sectional area [12,16], floodplain size [13,17], riverbank slopes [18], and substrate type [19]. Yet some studies also suggest that the presence, abundance, size and distribution of deciduous stems that are most frequently used by beavers, either as food or as building materials, are also crucial variables that should be considered within habitat models [20,21]. In order of preference, the most important species in the beaver's diet are trembling aspen (Populus tremuloides Michx.), willow (Salix spp.), balsam poplar (Populus balsamifera L.) and alder (Alnus spp.) [22]. According to [23], some woody plants, such as alder, are harvested by beavers mainly for the construction of dams rather than being utilised as a food source. The use of woody stems for shelter or food appears to depend upon the diameter of the stems rather than the species of plant [21].

Some studies have considered the effect of road or culvert presence on the distribution of dams within the landscape and most have found a positive association $[13,17,24,25]$. Two of these studies were conducted in boreal Alberta. In the first study, dams were observed on all inventoried roads, while in the second, the attractive effect of culverts was verified, though only at a scale of $300 \mathrm{~m}[24,25]$. Furthermore, research in New York State was undertaken specifically on habitat use by beavers near culverts; however, these studies dealt with highways rather than forest roads $[6,26]$. Nevertheless, the research has shown that oversized culverts allowing greater water flow were avoided by beavers [6]. Moreover, it demonstrated that the probability of site occupation by beavers was inversely related to the proportion of the roadside area that was devoid of woody vegetation and an increasing (>3\%) stream gradient [26].

In Quebec, the Abitibi-Témiscamingue region exhibits the highest beaver densities, with around 5.5 colonies $/ 10 \mathrm{~km}^{2}$ [27], together with the highest dam densities, with 4.01 to $6.22 \mathrm{dams} / 10 \mathrm{~km}^{2}$ [10]. Also, forest roads are widely established across the territory, harvesting activities are widely distributed due to their economic significance, and road density is constantly increasing [7], which has led to a growing number of conflicts with beavers. A better understanding of factors affecting the use of culverts by beavers on forest roads should allow managers to improve the localisation of new roads as well as culverts and, if necessary, target the most profitable locations for installing mitigation control systems. The objectives of this study were thus to identify the contribution of geomorphological, hydrological, anthropic and food factors, together with surrounding dam densities, to the risk of dam construction by beavers on new culverts. To do this, we compared with a model selection approach the 
relative weight that was assigned to each of the hypotheses that were identified a priori to potentially explain the presence of dams, over 128 culverts where the presence or absence of beaver dams had been confirmed on site. Our main prediction was that geomorphological factors would predominate explanations regarding the presence of beaver dams.

\section{Material and Methods}

\subsection{Study Area}

The study area covers $8000 \mathrm{~km}^{2}$ and is located in northwestern Quebec, within the heart of the boreal forest. Study sites were about $50 \mathrm{~km}$ away from the city of Rouyn-Noranda $\left(79.06^{\circ} \mathrm{W} ; 48.12^{\circ} \mathrm{N}\right)$. Located in the Abitibi region and James Bay lowlands, topographic relief of the study territory is relatively uniform and flat ( $235 \mathrm{~m}$ to $542 \mathrm{~m}$ above sea level) and mostly covered by glaciolacustrine clays left by the withdrawal of proglacial Lake Barlow-Ojibway [28]. Among other features, the region is characterised by a well-developed river system [27]. The extent of the study area is limited on its western edge by the Province of Ontario, by the Clay Belt at the southern and eastern boundaries, and by agricultural areas around Lake Abitibi at the northern side (Figure 1). In addition, the sites are mostly located in the western balsam fir-white birch bioclimatic subdomain, as described by [29]. In boreal mixedwoods, black spruce (Picea mariana [Mill.] BSP), jack pine (Pinus banksiana Lamb.), white or paper birch (Betula papyrifera Marsh.), and trembling aspen generally dominate the landscape. Balsam fir (Abies balsamea [L.] Mill.), white spruce (Picea glauca (Moench) Voss) and eastern white cedar (Thuja occidentalis L.) are also present in the territory. Throughout the study area, there are registered traplines. Yet beaver trapping is generally minimal due to the low market value of the furs.

As a first step, all practicable forest roads in the study area were visited to select sites. Each location corresponds to a culvert, which was characterised by the presence or absence of a beaver dam. When blocked culverts cause damage to roads, managers usually undertake dam removal and then engage professional trappers to eliminate the associated colony. This combined action often prevents fast rebuilding of the dam. However, such dam removals leave evidence (drained ponds, cluster swathes and eaten vegetation) in the area and we considered culverts showing such signs of beaver occupancy. Similarly, culverts exhibiting control of beaver flooding were also considered among the sites that beavers had occupied. Of 128 sampled culverts, 77 were used as dam building sites, while 51 were not.

\subsection{Characteristics Associated with Sampled Culverts}

\subsubsection{Geomorphological and Hydrological Variables}

Hydrographic data include catchment area (SBD), the ratio between flow level and culvert diameter (Ddia), catchment area gradient (inclBD), stream gradient (inclR), Strahler stream order (Order), cumulative length of all local (2-km radius) streams (kmR2km), and an index of riparian slopes (CoteP). All variables except CoteP and culvert diameter (field data) were extracted from a digital elevation model (DEM) available from the topographic database of Quebec (BDTQ), with 10-m resolution. Using the BASIN (version EX_02, ESRI, Redlands, CA, USA) (BASIN script allows catchment delineation from a point on a stream and calculation of the catchment's characteristics, together with generation of a stream network, display of a raindrop path traced from a point and display of elevations extracted from a grid (cell value) or from a surface, for a point defined by the user.) script in ARCGIS (http:/ / desktop.arcgis.com/fr/arcmap/10.3/tools/spatial-analysttoolbox/basin.htm), a drainage pattern for the study area was produced. Drainage basins are created by locating the pour points at the edges of the analysis window (where water would pour out of the raster), together with sinks, then identifying the contributing area above each pour point. When creating the linear layer representing the streams, the script automatically assigns an order to each segment using Strahler's method [30]. This information was retrieved directly for stream 
segments that contained a sampled culvert. Culverts that were located more than $150 \mathrm{~m}$ from a stream, depending upon the related upstream alignment, were not considered to be associated with a mapped stream and were thus assigned a value of zero in Strahler's order. By selecting a point on the map, BASIN also allows the estimation of areal surface that is being drained to that point. The drainage basins are identified within the analysis window by identifying ridgelines between basins. The theoretical surface of the catchment area was calculated for each culvert using such methods. The flow rate was calculated using the GSFdebit tool (version 10.3.002, Groupe Système Forêt, Québec, QC, Canada) for ArcGIS, which was developed by Groupe Système Forêt, Lévis, Québec (http:/ / www.gsf.ca/en-ca/applications/gsf-debit-pour-arcgis.aspx). The tool also calculates the average gradient of the catchment area, together with the main stream gradient. Since we knew that flow rate variation would be small due to regional topography and the streams that were sampled, we used the ratio between the estimated flow level and culvert diameter as an indicator of the amount of water available versus bottlenecks to be blocked.

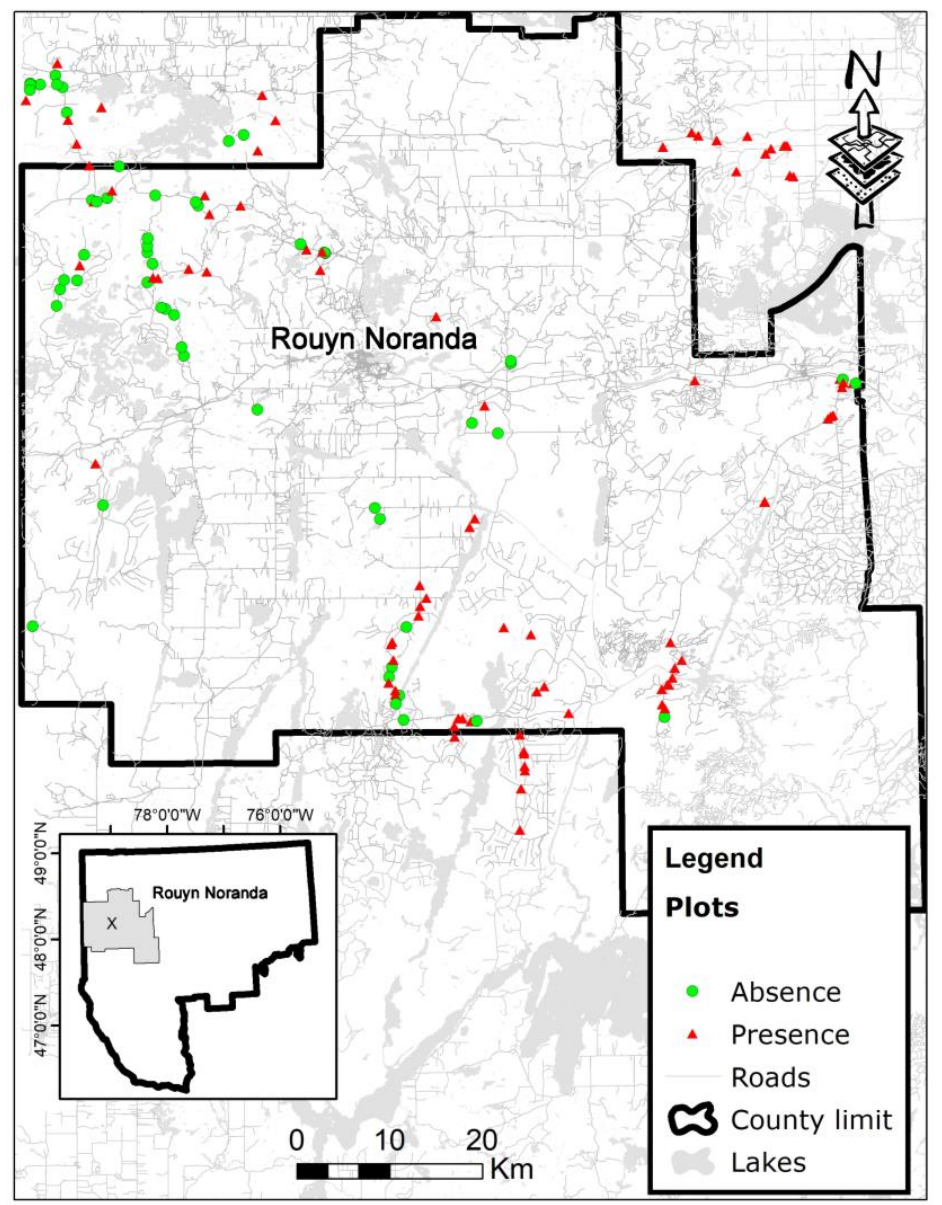

Figure 1. Locations in Abitibi, Québec, of 128 culverts that were sampled for the presence or absence of beaver dams.

Disparities were observed when overlap was calculated between readily available "base de données topographiques du Québec" (BDTQ) water systems and that created with BASIN. Thus, several catchment limit differences were observed, together with those for other resulting variables: flow level, catchment area gradient and stream gradient. To take into account the reality that we felt best represented by the BDTQ water system (derived through photo interpretation), we retained coarse variables from the DEM and compared them to those that were obtained using water systems that were available in the BDTQ database to validate a systematic method of extraction. 
The aim was to develop a practical tool that could be used by land managers, considering the extremely useful potential applications of current software developments. In order to see whether the density of available streams had an effect on the density of beavers that were likely to colonise the culverts, the cumulative length of all local (2-km radius) streams of each sampled culvert was also calculated using BASIN script. Lastly, the CoteP riparian slope index was measured using a clinometer for both riverbanks that were upstream of roads. Gradient degrees were divided into four classes: Class 0 (null slope), Class 1 (0.1 to 3\%), Class 2 (3.1 to 6\%) and Class $3(>6 \%)$. Classes of each riverbank were then summed to provide a rating of riparian slope for each culvert. We expected that higher values would be associated with lower dam-site selection by beavers, because of higher risks of floods.

\subsubsection{Variables Associated with the Availability of Food and Dam Building Materials}

Dietary variables and building material availability were estimated according to hardwood dominance (Hardw) and alder (Alnus sp.) presence (Al). This information was derived from current provincial forest inventory ecoforestry maps. Areas (ha) that were covered by deciduous or mixed type stands-dominated by trembling aspen or white birch in our study area-were added to a sampling area measuring $200 \mathrm{~m}$ in radius around each culvert. Sampling area radius was established based upon consultations with trappers regarding their experience with beaver foraging behaviour in our study area. The presence of alders over at least 1 ha was subsequently recorded and compiled as a categorical variable (presence or absence) for each culvert.

\subsubsection{Anthropogenic Variables and Characteristics of Culverts}

These data refer to the height of the road (embankments) and road age category. Road embankment height was measured directly on sites. Road embankment height was measured upstream, from contact with the water stream to the highest point that was perpendicular to the road bed. To determine the construction year of roads, we used the harvest year and sylvicultural activities close to the roads that were registered in annual forest operation reports. A spatial chronosequence (1985, 1995, 2000 and 2005) from classified Landsat images [31] was also used to validate and complete the information for more recent roads. Given the narrow range that was obtained for the age distribution of roads, with recent roads much less represented in our sample, we decided to use two age groups in subsequent analyses: group 0 for recent roads (construction year $\geq 1985$ ) and group 1 for older roads $(<1985)$.

\subsubsection{Local Abundance of Beaver Dams}

Beaver density is generally assessed by counting the number of lodges, which was information not readily available in our study area. However, precise locations of beaver dams (at least $10 \mathrm{~m}$ in length) were available on the BDTQ map of streams. Although we are aware that dam abundance data might not provide a good surrogate for beaver colonies, we hypothesised that the local abundance of existing beaver dams might influence the likelihood of using a culvert as a new dam site. The local abundance of beaver dams was thus estimated according to the number of surrounding dams that were within two kilometres of each culvert $(\mathrm{NbB})$.

\subsection{Statistical Analyses}

Logistic regression was used to predict the probability of dams near culverts. Each model represents a hypothesis that could explain the presence of beavers near culverts, and which contains one or more variables based upon biological knowledge of beaver habitat. Models refer to geomorphology and hydrology, food and dam-building materials, human factors, and surrounding beaver populations (Table 1). Two models were compared in the case of geomorphology and hydrology: a first model was obtained from DEM data (HYDRO1) and a second one was obtained from BDTQ (HYDRO2), which also involves two global models (Global1 and Global2), totalling eight models. Lastly, to take into account 
the effect of time since road construction, the time that had elapsed between road construction and sampling was added to each model as an offset.

All models subsequently were compared with one another, using the Akaike information criterion (AICc) [32]. Weighted estimates and unconditional standard errors were calculated for each variable in the best models. The effects of variables were determined according to a $95 \%$ confidence interval. To illustrate the magnitude of the effect of each variable, multi-model inference was determined for the predicted probabilities from each model, for the range of values that were covered by each variable of interest, by keeping the other variables fixed. All statistical analyses were performed in $\mathrm{R}$ (v. 2.7.2; http://probability.ca/cran/).

Table 1. Variables included in candidate models to test different hypotheses explaining the presence of dams.

\begin{tabular}{|c|c|}
\hline Models & Variables * \\
\hline HYDRO1 & $\mathrm{SBD}+\mathrm{Ddia}+$ inclBD + inclR + Order + kmR2km + CoteP + AGE \\
\hline HYDRO2 & SBDbdtq + Ddiabdtq + inclBDbdtq + inclRbdtq + Order + kmR2km + CoteP + AGE \\
\hline FOOD\&CONST & Hardw + AI + AGE \\
\hline BEAVER & $\mathrm{NbB}+\mathrm{AGE}$ \\
\hline GLOBAL1 & $\mathrm{SBD}+\mathrm{Ddia}+$ inclBD +inclR +Order + kmR2km +CoteP + Hardw + AI + Embank + NbB + AGE \\
\hline GLOBAL2 & SBDbdtq + Ddiabdtq + inclBDbdtq + inclRbdtq + Order + kmR2km + CoteP + Hardw + AI + Embank + NbB + AGE \\
\hline $\begin{array}{l}* \mathrm{SBD}, \text { catchr } \\
\text { stream gradi } \\
\text { riverbank slo } \\
\text { ratio from BD } \\
\text { mixed forest } \\
\text { Embank, roa }\end{array}$ & $\begin{array}{l}\text { hent area surface (ha); DdiA, flow level:culvert diameter ratio; inclBD, catchment area gradient; inclR, } \\
\text { ent; Order, Strahler order; kmR2km, cumulative length of all local (2-km radius) streams (km); CoteP, } \\
\text { pe; SBDbdtq (ha), catchment area surface from BDTQ (ha); Ddiabdtq, flow level and culvert diameter } \\
\text { TQ; inclBDbdtq, catchment area gradient from BDTQ; inclRbdtq, stream gradient from BDTQ; Hardw, } \\
\text { or deciduous area (ha); Al, alder presence; NbB, number of surrounding dams within 2-km radius; } \\
\text { d embankment height (m); AGE, road age. }\end{array}$ \\
\hline
\end{tabular}

\section{Results}

Regardless of whether dams were incorporated into culverts or not, the range of estimated values for each variable (HYDRO1, HYDRO2) was similar in both cases (Table 2). Further, when comparing the average value with the range of values for each variable, few sampled culverts had values close to the upper limit (Table 2). Indeed, most sampled culverts exhibited values closer to the lower limit. 
Table 2. Descriptive data for 12 study variables that were used to explain the presence or absence of dams.

\begin{tabular}{ccccccccc}
\hline \multirow{2}{*}{ Variables * } & \multicolumn{3}{c}{ Culverts without Dams } & \multicolumn{5}{c}{ Culverts with Dams } \\
& Max & Median ** & SD & Min & Max & Median ** & SD \\
\hline SBD & 0.01 & 1015.49 & 98.62 & 32.35 & 0.01 & 693.67 & 52.31 & 12.47 \\
Ddia & 0 & 15.55 & 0.87 & 0.33 & 0 & 7.27 & 1.00 & 0.17 \\
inclBD & 0 & 13.67 & 2.89 & 0.53 & 0 & 15.71 & 3.77 & 0.45 \\
inclR & 0 & 28.91 & 2.18 & 0.65 & 0 & 17.39 & 2.88 & 0.46 \\
Order & 0 & 4 & 1 & & 0 & 4 & 1 & \\
kmR2km & 32.53 & 53.62 & 40.64 & 0.68 & 32.01 & 52.62 & 38.94 & 0.48 \\
CoteP & 0 & 6 & 2 & & 0 & 6 & 2 & \\
SBDbdtq & 0.01 & 693.67 & 330.87 & 91.76 & 0.01 & 3092.28 & 233.32 & 51.33 \\
Ddiabdtq & 0 & 9 & 1.54 & 0.24 & 0 & 14.05 & 2.18 & 0.30 \\
inclBDbdtq & 0 & 11.96 & 3.96 & 0.43 & 0 & 15.71 & 5.25 & 0.42 \\
inclRbdtq & 0 & 28.91 & 2.36 & 0.62 & 0 & 17.39 & 2.73 & 0.42 \\
Hardw & 0 & 12.56 & 7.12 & 0.53 & 0 & 12.56 & 7.04 & 0.40 \\
AI & & & 0.18 & & & & 0.26 & 3.81 \\
NbB & 4 & 128 & 47.16 & 4.66 & 4 & 176 & 57.73 & 0.10 \\
Embank & 0.60 & 4.90 & 1.84 & 0.14 & 0.30 & 7.00 & 1.43 & 1 \\
AGE & & & 1 & & & & & 0.43 \\
\hline
\end{tabular}

* See Table 1 for description of variables. ${ }^{* *}$ The median is given for CoteP and AGE, and proportion of AI variable.

Following the comparison of eight candidate models using AICc, two plausible models emerged from among those that were set a priori to explain the presence of dams near culverts. The first model contains only geomorphological and hydrological BDTQ variables (HYDRO2), with a delta AICc weight of 0.46 (Table 3). The second model includes the height of the embankment (ANTHROPO), with an AICc delta of 0.34 and an AICc weight of 0.38 (Table 3). According to evidence ratio statistics, the HYDRO2 model is approximately equivalent to the ANTHROPO model and roughly seven times better than the next model, i.e., the global model with BDTQ data (GLOBAL2). All other models can be dismissed as being less plausible, since AICc deltas are close to or above 4, and AICc weights are near or below 0.05 (Burnham and Anderson, 2002).

Table 3. Results of model selection using the Akaike information criterion (AIC).

\begin{tabular}{cccccc}
\hline Models * & $\begin{array}{c}\text { Number of } \\
\text { Parameters (K) }\end{array}$ & AICc & Delta AICc & AICc Weight & $\begin{array}{c}\text { Cumulative } \\
\text { Weight }\end{array}$ \\
\hline HYDRO2 & 9 & 171.0591 & 0 & 0.4558 & 0.4558 \\
ANTHROPO & 3 & 171.3987 & 0.3396 & 0.3846 & 0.8404 \\
GLOBAL2 & 13 & 174.8605 & 3.8013 & 0.0681 & 0.9085 \\
BEAVER & 3 & 175.0607 & 4.0015 & 0.0616 & 0.9702 \\
FOOD & 3 & 178.0255 & 6.9664 & 0.014 & 0.9842 \\
FOOD\&CONST & 4 & 179.0141 & 7.955 & 0.0085 & 0.9927 \\
GLOBAL1 & 13 & 180.5877 & 9.5286 & 0.0039 & 0.9966 \\
HYDRO1 & 9 & 180.8446 & 9.7855 & 0.0034 & 1 \\
\hline
\end{tabular}

*HYDRO2: geomorphological and hydrological variables with adjusted data; ANTHROPO: anthropogenic variables; Global2: global model with adjusted data; BEAVER: variable related to dam density and age of roads; FOOD: variable related to food; FOOD\&CONST: variables related to food availability and dam-building materials; Global1: global model with DEM; HYDRO1: geomorphological and hydrological variables with DEM.

Multi-model inference allowed us to identify catchment area surfaces (SBDbdtq), cumulative length of all local (2-km radius) streams $(\mathrm{kmR} 2 \mathrm{~km})$ around study culverts and road embankment heights (Embank) as all having a negative effect on the probability of encountering beaver dams (Table 4; Figure 2). BDTQ level flow and culvert diameter ratio (Ddiacor) had, in turn, a positive effect (Table 4; Figure 2). All other variables in the best two models had no effect, since they all included 0 in their respective confidence intervals (Table 4). Finally, the adjustment test of Le Cessie 
and Van Houwelingen [33] over the HYDRO2 model with BDTQ data confirms a good fit ( $p=0.987$ ). Moreover, according to Cox and Snell's $R$ test [34] for the same model, about 18.7\% of the probability estimates for culvert dams may be explained by the study variables $\left(R^{2}=0.187\right)$.

Table 4. Results of multi-model inference for the variables included in the top two models (HYDRO2, ANTROPHO).

\begin{tabular}{ccccc}
\hline Variables * & Beta & $\begin{array}{c}\text { Standard } \\
\text { Deviation (SD) }\end{array}$ & Lower Limit & Upper Limit \\
\hline SBDbdtq & -0.0019 & 0.0008 & -0.0034 & -0.0004 \\
kmR2km & -0.1036 & 0.0474 & -0.1966 & -0.0107 \\
Embank & -0.5321 & 0.2424 & -1.0072 & -0.0571 \\
Ddiabdtq & 0.3883 & 0.1905 & 0.0149 & 0.7616 \\
inclBDbdtq & 0.0877 & 0.0826 & -0.0741 & 0.2495 \\
inclRbdtq & -0.0545 & 0.0625 & -0.1769 & 0.0680 \\
Order & 0.0726 & 0.2153 & -0.3493 & 0.4946 \\
CoteP & -0.1133 & 0.1083 & -0.3256 & 0.0989 \\
NbB & 0.0099 & 0.0064 & -0.0027 & 0.0225 \\
AGE & -0.4803 & 0.5168 & -1.4932 & 0.5326 \\
\hline
\end{tabular}

* See Table 1 for description of variables.

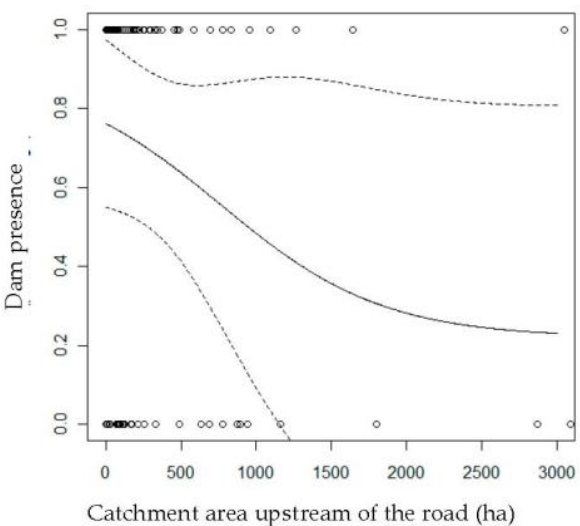

(a)

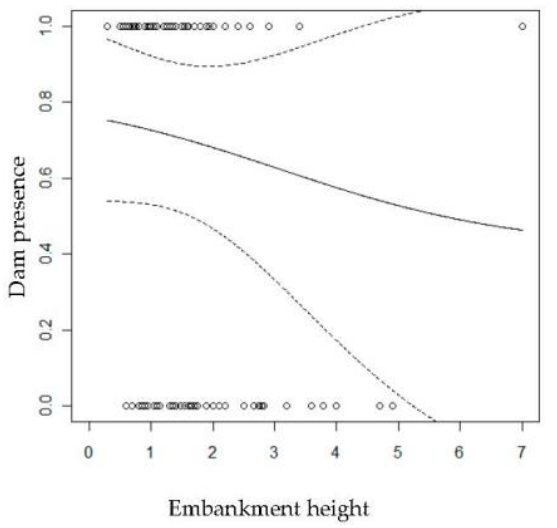

(c)

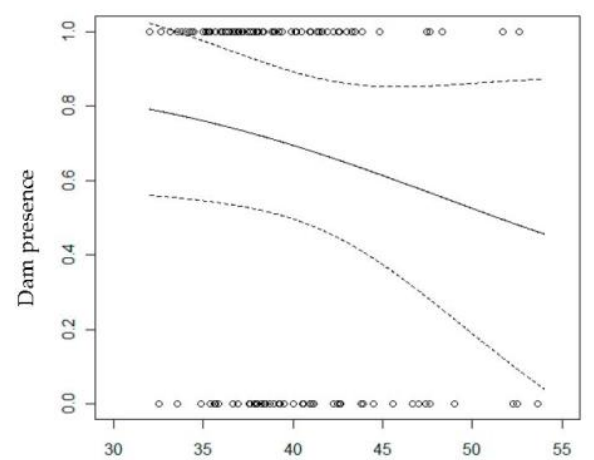

The number of $\mathrm{km}$ of streams within $2 \mathrm{~km}$ radius around the culvert

(b)

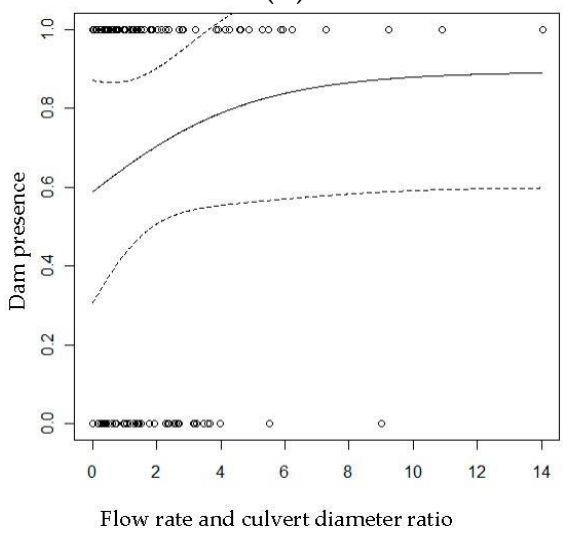

(d)

Figure 2. Probability of dam presence near culverts according to (a) BDTQ catchment area upstream of the road, (b) the number of $\mathrm{km}$ of streams within $2-\mathrm{km}$ radius around the culvert, (c) embankment height and (d) BDTQ flow rate and culvert diameter ratio. The dotted lines represent $95 \%$ confidence bands and dots represent sample culverts $(n=128)$. 


\section{Discussion}

\subsection{Variables Predictive Power and Support of Submitted Hypotheses}

As suggested by reports in the literature [12,13,15,21] and our hypotheses, the effects of geomorphological and hydrological parameters were the most significant in predicting the presence of beaver dams near culverts. In addition, we observed that coarse variables from the DEM (HYDRO1) were not sufficient to make valid predictions. Indeed, the model (HYDRO2) with the BDTQ water system data was the most suitable, whereas models with the DEM alone were the least plausible. Similarly, the model that was based upon anthropogenic factors also has explanatory power, yet assumptions on dietary variables and the local abundances of beaver dams were not supported by the model selection process.

\subsubsection{Effects of Geomorphic and Hydrologic Variables}

Some geomorphology and hydrology variables that were included in the model (HYDRO2) appear to exert a greater effect than others when predicting the probability of dams in culverts. This is particularly true regarding the values of catchment area surface (SBDbdtq), level flow and culvert diameter ratio (Ddiabdtq), together with the cumulative length of all local (2-km radius) streams (kmR2km).

A high proportion of beaver dams was located within medium-sized catchment areas between 500 and 5000 ha, as was already observed in a previous study that was conducted in the upper Coastal Plain of South Carolina [13]. At the lower end of this catchment area gradient, the authors concluded that small watersheds are inadequate for the establishment of beavers due to the intermittent presence of surface water. On the higher end of this gradient, excessive water velocity and other physical problems that are related to the amplitude of discharge reduced the suitability of the habitat for beavers in large river basins. Since the observed values in this study ranged from 0 to 3000 hectares, we expected that the relationship between the probability of occurrence and the catchment area surface would be positive. The negative relationship that we obtained could be due to the fact that beavers may create ponds, even on culverts that are located in a low catchment area, provided that there is a minimal water flow, which likely exists given the boreal context of our study area.

Since level flow variation range is relatively small in relation to the topography and study streams, we evaluated the relationship between level flow and culvert diameter. As expected, this ratio results in a positive relationship with the likelihood of beaver dam construction. On one hand, a strong ratio suggests a significant amount of water (high flow level) or a small culvert diameter; on the other hand, these characteristics were both likely to make sites attractive to beavers. Indeed, high flow levels ensure considerable water input throughout the year, and small culverts may limit the efforts to build dams. Finally, we had hypothesised that the number of streams near culverts could have increased the chances of settlement of one or more colonies and that of colonisation of culverts. However, the negative effect of this variable suggests otherwise: where streams are naturally rare, fewer potential spots for dam settlement exist, which thus increases the likelihood of dam construction on culverts.

\subsubsection{Effects of Anthropogenic Variables}

A positive selection effect has previously been shown for dam sites that allow the creation of larger ponds [35]. Culvert sites with high road embankments would thus be more likely to be colonised by beavers since they allow greater water blockage. Indeed, there is generally a strong correlation between embankment height and culvert diameter. In this sense, we suggest that the negative relationship that was obtained with road embankments may not be linked to the avoidance of sites allowing the creation of larger ponds, but rather to sites with greater diameter culverts [6]. 


\subsubsection{Effects of Dietary Related Variables}

Like the data that were obtained by [10], our results suggest that the availability of hardwood species neither presents a factor limiting food in the study area, nor do they represent a constraint on the availability of construction materials. It is even likely that beavers sometimes use coniferous stems for the construction of dams or huts [25]. We also have no information regarding the purpose of the ponds that were created by roadside dams. Indeed, we know that beavers build a primary pond (one containing a hut) and, sometimes, secondary ponds that provide access to more food or which maintain more stable water levels upstream [36]. In our case, we noted that most ponds that were observed in the field did not contain a hut, while other habitat studies have generally related to colonies and, therefore, primary ponds. It is thus possible that some variables that proved significant in these other studies do not provide information when it comes to secondary ponds, which could be the case for hardwoods that are used primarily as food. It is also suggested in the literature that dietary parameters are difficult to consider in the case of beaver habitat studies, since beavers greatly shape their habitat themselves [15]. Consequently, riparian vegetation can be greatly modified.

\subsection{Study Limitations}

In this study, adjusted estimates were very low ( $<1$; Table 3), even for all four of the most important variables, which suggests weak relationships. We believe that within the range of observed values for each variable, there is no threshold at which it would be more difficult for beavers to create dams, which reduces the discrimination capacity of the study. This can be explained by the fact that sampling sites are limited to culverts, that is to say, small-scale streams, as compared to sites where priority is given to the construction of short bridges.

It should also be mentioned that all geomorphological and hydrological data for this study came from a digital elevation model that was designed for level curves, with ten-metre intervals, from Quebec's topographic database (BDTQ). Since the topography is flat, it may be necessary to travel long horizontal distances to attain a ten-metre rise in elevation. In such cases, basins or topographical variations may exist, but they are much more subtle than level curve detail and, thus, not adequately represented. This could explain the presence of catchment areas with an area close to zero, together with the resulting variables (flow, catchment area and stream slope). Given the progress and opportunities created by new technology, the promising use of LiDAR-based remote sensing, for example, could contribute to improving our models [37].

Furthermore, classification errors may have occurred in terms of data regarding the presence of dams in culverts. Indeed, there is no record of culvert maintenance. Certain site indices allowed us to know whether culverts had been recently used by beavers or not, but false absences may occur in some cases. In addition, culverts are sometimes replaced. Site modifications and machinery may lead us to believe that dams were absent, whereas culverts are often replaced precisely to eliminate the harmful presence of a beaver dam.

Finally, we may wonder whether a road itself might represent a very influential factor in explaining the presence of dams in the culverts. If so, the presence of the road alone in many cases may account for a larger portion of the phenomenon better than all other variables together, thereby justifying in part the low predictive power of the models (Cox and Snell's R equivalent to 18.7\%).

\subsection{Management Implications}

One of our main conclusions is that the predictive power of our models proved to be insufficient to make them reliable for implementation in the context of road network management. First, regarding the extent of the observed values for the study variables, the probability of dam presence is always relatively high ( $>50 \%$, see Figure 2$)$, suggesting that virtually all territory exhibits a sufficiently high potential for dam construction and the risk is significant. Also, for all four variables that accounted for the most important effects, the confidence interval on the predicted probability of dam presence varies 
from nearly $50 \%$ to $100 \%$ over the whole range of observed values (Figure 2). In that sense, it would be appropriate to take into account the potential presence of a dam when planning roads, rather than seeking places that would allow for minimisation of the problem.

We suggest that the incorporation of mitigation measures, such as pre-dams, should be planned at the time of construction of roads. Pre-dams are short semicircular, circular, or rectangular fences that divert the beavers' attention away from a culvert to the fence [38]. These devices are also called diversion dams because, unlike beaver deceivers which function by preventing damming, pre-dams are intended to be dammed. We believe that in many cases, this would reduce both the cost of culvert maintenance, and that related to the installation of the pre-dam itself. Indeed, the installation costs are often lower when performed at the time of construction, since the machinery is already present on sites.

\section{Conclusions}

In short, among the factors that were considered in this study, i.e., geomorphology and hydrology, food availability, human factors and the density of surrounding dams, the study demonstrated that geomorphology and hydrology variables are the most important in explaining the presence of dams in culverts. However, the predictive power of our models was insufficient and unreliable in the context of road network management. These variables were considered, since the catchment area upstream of the road and the cumulate length of all local (2-km radius) streams have a negative effect on the probability of the presence of a dam, whereas the ratio between flow and culvert diameter has a positive effect. In addition, the height of the embankment, which most often refers to the diameter of the culvert, also has a negative effect on the probability of dam presence.

In most cases, the predicted probability of dam construction in culverts was equal to or greater than $50 \%$, which obviously means that the entire study area is highly susceptible to beaver establishment. The promise offered by LiDAR remote sensing technology could contribute to improving our models. Until then, it would be preferable to install mitigation measures such as pre-dams during road construction. This would likely reduce the occurrence of conflicts with beavers and, thus, reduce the maintenance costs of forest roads. In addition, we know that the pre-dam system is less expensive when done at the time of construction of roads compared to a breach in the road caused by flooding (washout), because the machinery required for the operation is already in place (St-Amant, pers. comm.).

Research Perspective

- Conducting the same kind of research in a hilly region could establish thresholds and confirm whether study variables are truly potential explanatory variables.

- $\quad$ Using more specific topographic data (though more expensive), such as those acquired with LIDAR, to determine whether a more detailed and more realistic geomorphological and hydrological characterisation of the landscape would provide a better explanation of observed phenomena. More accurate data would also allow us to calculate the potential catchment flooded area according to the height of embankments. Indeed, we know that flood area has a positive effect on the presence of beaver dams, as has been determined in other habitat studies for this species.

- Assessing the contribution of the presence of the road as such to explain the presence of dams at culverts. Indeed, it is believed that in some cases, beavers preferentially set their dams at the side of roads, although other aspects of habitat would be less favourable.

Acknowledgments: The original data set was obtained from the Ministry of Energy and Natural Resources of Quebec (MERNQ). We especially thank Jean Marc St Amant (Tembec) for providing assistance with field data and knowledge of study area, Roger De Denus R.I.P. (local trapper association) for useful information about beaver behaviour, and Pierre Cartier, Annie Malenfant and Francis Martin (Cégep Abitibi Témiscamingue) for their participation in the fieldwork. Marc J. Mazerolle provided helpful comments on the statistical data analyses. We thank W.F.J. Parsons for reviewing the English language. We are most grateful to the Ministry of Forests, Wildlife and Parks of Quebec (MFFPQ) for its financial support. 
Author Contributions: All co-authors contributed to the conception and design of the study as well as the writing of the manuscript; G.T. conducted the field work and analyzed the data.

Conflicts of Interest: The authors declare no conflicts of interest.

\section{References}

1. Payne, N.F.; Peterson, R.P. Trends in complaints of beaver damage in Wisconsin. Wildl. Soc. B 1986, 14, 303-307.

2. Miller, J.E.; Yarrow, G.K. Beavers-Prevention and Control of Wildlife Damage; Institute of Agriculture and Natural Resources, University of Nebraska: Lincoln, NE, USA, 1994.

3. McKinstry, M.C.; Anderson, S.H. Attitudes of private and public-land managers in Wyoming, USA, toward beaver. Environ. Manag. 1999, 23, 95-101.

4. Newbill, C.B.; Parkhurst, J. Managing Wildlife Damage: Beavers (Castor canadensis); Virginia Cooperative Extension; Virginia Polytechnic Institute and State University: Blacksburg, VA, USA, 2000; pp. 1-8.

5. Forman, R.T.T.; Alexander, L.E. Roads and their major ecological effects. Annu. Rev. Ecol. Syst. 1998, 29, 207-231.

6. Jensen, P.G.; Curtis, P.D.; Leahnert, M.E.; Hamelin, D.L. Habitat and structural factors influencing beaver interference with highway culverts. Wildl. Soc. B 2001, 29, 654-664.

7. Coulombe, G.; Huot, J.; Arsenault, J.; Bauce, É.; Bernard, J.-T.; Bouchard, A.; Liboiron, M.-A.; Szaraz, G. Commission D'étude Sur La Gestion de La Forêt Publique Québécoise: Rapport Décembre 2004. 2004; p. 314. Available online: https: / www.mffp.gouv.qc.ca/publications/forets/consultation/rapport-coulombe.pdf (accessed on 5 October 2017).

8. MRNFQ. Ressources et Industries Forestières: Portrait Statistique, Édition 2007; Direction du Développement de L'Industrie des Produits Forestiers, Gouvernement du Québec: Québec, Canada, 2007.

9. Langlois, S.; Decker, T. The Use of Water Flow Devices and Flooding Problems Caused by Beaver in Massachusetts; Massachusetts Division of Fisheries and Wildlife: Westborough, MA, USA, 1997.

10. Lapointe St-Pierre, M.; Labbé, J.; Darveau, M.; Imbeau, L.; Mazerolle, M.J. Factors affecting abundance of beaver dams in forested landscapes. Wetlands 2017, 37, 941-949. [CrossRef]

11. Touihri, M.; Labbé, J.; Imbeau, L.; Darveau, M. Spatial Modelling of Beaver (Castor canadensis Kuhl) Habitat: Review of the Relative Effects of Geomorphology, Food Availability and Anthropogenic Infrastructure. Écoscience 2017. [CrossRef]

12. Beier, P.; Barrett, R.H. Beaver habitat use and impact in Truckee River Basin, California. J. Wildl. Manag. 1987, 51, 794-799.

13. Jakes, A.F.; Snodgrass, J.W.; Burger, J. Castor canadensis (Beaver) impoundment associated with geomorphology of southeastern streams. Southeast. Nat. 2007, 6, 271-282. [CrossRef]

14. Snodgrass, J.W. Temporal and spatial dynamics of beaver-created patches as influenced by management practices in a south-eastern American landscape. J. Appl. Ecol. 1997, 34, 1043-1056. [CrossRef]

15. Suzuki, N.; McComb, W.C. Habitat classification models for beaver (Castor canadensis) in the streams of the Central Oregon Coast Range. Northwest Sci. 1998, 72, 102-110.

16. Barnes, D.M.; Mallik, A.U. Habitat factors influencing beaver dam establishment in a Northern Ontario watershed. J. Wildl. Manag. 1997, 61, 1371-1377.

17. McComb, W.C.; Sedell, J.R.; Buchholz, T.D. Dam-site selection by beavers in an eastern Oregon basin. Great Basin Nat. 1990, 50, 273-281.

18. Dieter, C.D.; McCabe, T.R. Factors influencing beaver lodge-site selection on a prairie river. Am. Midl. Nat. 1989, 122, 408-411. [CrossRef]

19. Howard, R.J.; Larson, J.S. A stream habitat classification system for beaver. J. Wildl. Manag. 1985, 49, $19-25$. [CrossRef]

20. Fryxell, J.M.; Doucet, C.M. Diet choice and the functional response of beavers. Ecology 1993, 64, 1297-1306. [CrossRef]

21. Barnes, D.M.; Mallik, A.U. Use of woody plants in construction of beaver dams in northern Ontario. Can. J. Zool. 1996, 74, 1781-1786. [CrossRef]

22. Denney, R.N. A Summary of North American Beaver Management, 1946-1948; Colorado Game and Fish Department: CO, USA, 1952; Volume 28, p. 64. 
23. Slough, B.G. Beaver food cache structure and utilization. J. Wildl. Manag. 1978, 42, 644-646. [CrossRef]

24. Martell, K.A. Patterns of Riparian Disturbance in Alberta's Boral Mixedwood Forest: Beavers, Roads and Buffers. Master's Thesis, Department of Renewable Resources, University of Alberta, Edmonton, AB, Canada, 2004; p. 188.

25. Flynn, N.J. Spatial Associations of Beaver Ponds and Culverts in Boreal Head Water Streams. Master's Thesis, Department of Renewable Resources, University of Alberta, Edmonton, AB, Canada, 2006; p. 108.

26. Curtis, P.D.; Jensen, P.G. Habitat features affecting beaver occupancy along roadsides in New York State. J. Wildl. Manag. 2004, 68, 278-287. [CrossRef]

27. Lafond, R.; Pilon, C.; Leblanc, Y. Bilan Du Plan D'Inventaire Aérien des Colonies de Castors Au Québec (1989-1994); Société de la Faune et des parcs du Québec, Direction du Développement de la Faune: Québec, QC, Canada, 2003; 89p.

28. Vincent, J.S.; Hardy, L. L'évolution et l'extension des lacs glaciaires Barlow et Ojibway en territoire québécois. Géogr. Phys. Quat. 1977, 31, 357-372. [CrossRef]

29. Blouin, J.; Berger, J.-P. Guide de Reconnaissance des Types Écologiques de la Région Écologique 5a-Plaine de L'Abitibi; Ministère des Ressources Naturelles du Québec, Forêt Québec, Direction des Inventaires Forestiers, Division de la Classification Écologique et Productivité des Stations: Québec, QC, Canada, 2002.

30. Strahler, A.N. Quantitative analysis of watershed geomorphology. Trans. Am. Geophys. Union 1957, 38, 913-920. [CrossRef]

31. Valeria, O.; Laamrani, A.; Beaudoin, A. Monitoring the state of a large boreal forest region in eastern Canada through the use of multitemporal classified satellite imagery. Can. J. Remote Sens. 2012, 38, 91-108. [CrossRef]

32. Burnham, K.P.; Anderson, D.R. Model Selection and Multimodel Inference: A Practical Information-Theoretic Approach, 2nd ed.; Springer: New York, NY, USA, 2002.

33. Van Houwelingen, J.C.; Le Cessie, S. Predictive value of statistical models. Stat. Med. 1990, 9, $1303-1325$. [CrossRef] [PubMed]

34. Cox, D.R.; Snell, E.J. Analysis of Binary Data, 2nd ed.; John Wiley \& Sons, Ltd.: Hoboken, NJ, USA, 1990.

35. Johnston, C.A.; Naiman, R.J. Aquatic patch creation in relation to beaver population trends. Ecology 1990, 71, 1617-1621. [CrossRef]

36. Baker, B.W.; Hill, E.P. Beaver (Castor canadensis). In Wild Mammals of North America: Biology, Management and Conservation; Feldhamer, G.A., Thompson, B.C., Chapman, J.A., Eds.; Johns Hopkins University Press: Baltimore, MD, USA, 2003; pp. 288-310.

37. Akay, A.E.; Oğuz, H.; Karas, I.R.; Aruga, K. Using LiDAR technology in forestry activities. Environ. Monit. Assess. 2009, 151, 117-125. [CrossRef] [PubMed]

38. Brown, S.; Brown, J. (Eds.) How to Control Beaver Flooding, Beavers; Wetlands \& Wildlife Inc.: Dolgeville, NY, USA, 1999; p. 13329. 